\title{
The Relationship of Temperament and Character Dimensions to Perceived Parenting Styles in Childhood: A Study of a Japanese University Student Population
}

\author{
Mika S. Takeuchi ${ }^{*},{ }^{2}$ Hitoshi Miyaoka ${ }^{2}$, Masao Suzuki $^{3}$, Atsuko Tomoda ${ }^{4}$, Akiko I. Yokoo ${ }^{5}$, \\ Risa Tsutsumida ${ }^{6}$ and Toshinori Kitamura ${ }^{7}$ \\ ${ }^{1}$ Jiyugaoka Sanno College School of Business, Tokyo, Japan \\ ${ }^{2}$ Department of Psychiatry, Kitasato University School of Medicine, Kanagawa, Japan \\ ${ }^{3}$ Waseda University School of Human Sciences, Saitama, Japan \\ ${ }^{4}$ Department of Psychology, Saitama Institute of Technology, Saitama, Japan \\ ${ }^{5}$ Tokyo Kasei-Gakuin University, Tokyo, Japan \\ ${ }^{6}$ Psychology of Disorders and Dysfunctions, Kyusyu Lutheran College School of Humanities, Kumamoto, Japan \\ ${ }^{7}$ Kitamura Institute of Mental Health, 8-12-4-305 Akasaka, Tokyo, Japan
}

\begin{abstract}
To examine the association between perceived parenting styles in childhood and temperament and character dimensions in adolescence and early adulthood, 836 college students in Japan were assessed using the Temperament and Character Inventory (TCI) and the Parental Bonding Questionnaire (PBI). A path analysis revealed that Novelty Seeking and Harm Avoidance were associated with low Self-Directedness and low Cooperativeness; Novelty Seeking, Reward Dependence, and Persistence were associated with Self-Transcendence; and Reward Dependence was associated with Cooperativeness. It also showed that Perceived Parenting (parents' high Care and low Overprotection) was associated with low Harm Avoidance and high Persistence, and was directly associated with Self-Directedness, Cooperativeness, and low Self-Transcendence. These findings suggest that perceived parenting styles are more associated with character dimensions than temperament dimensions. This link was direct or indirect via temperament dimensions.
\end{abstract}

Keywords: temperament, character, perceived parenting style.

\section{INTRODUCTION}

Parenting styles are important in both clinical and research settings. It is believed that children's development is influenced by their interaction with the outer world and, in particular, by the attitudes of their parents towards them. Although parenting styles may be viewed from a variety of perspectives, many studies have adopted the view that these styles have at least two dimensions $[1,2]$--- responsiveness (acceptance/care) and demandingness (control/overprotection). Responsiveness refers to the extent to which parents foster individuality and self-assertion in their children. This includes the warmth a parent exhibits towards his or her child. Demandingness relates to the requirements parents place on children via behavioural regulation and direct confrontation. Parker [3] viewed perceived parenting styles differently, postulating that Care and Overprotection are their two main dimensions. Parker, Tupling et al. [4] created a retrospective self-report of parental rearing, the Parental Bonding Questionnaire (PBI). Affectionless control

*Address correspondence to this author at the Jiyugaoka Sanno College, 6-3915, Todoroki, Setagaya-ku, Tokyo, 158-8630, Japan; Tel: +81-(0)3-37044011; Fax: +81-(0)3-3704-7859;

E-mails: TAKEUCHI_Mika@hj.sanno.ac.jp,Micah_s2@jcom.home.ne.jp (low Care and high Overprotection) has been repeatedly reported to be associated with poor psychological adjustment, leading to symptoms such as clinical depression (e.g., [3, 5]). Although factor analyses of the PBI have demonstrated that these two dimensions would correspond to two factors, they are moderately correlated with each other [6]. Because parenting styles may exert a strong influence on children's psychological development, one can speculate that personality development will be affected by parenting styles as well. Personality has been viewed as having both genetically determined components (e.g., [7]) as well as those that develop through interactions with the environment [8]. Personality development has been studied in its link with the parenting styles in childhood.

Cloninger's seven-factor model is unique in that he divided personality into (1) temperament, referring to automatic emotional responses to experiences that are moderately heritable and stable throughout life, and (2) character, referring to self-concepts and individual differences in goals and values formed through sociocultural learning [9]. The temperament dimensions include Novelty Seeking, Harm Avoidance, Reward Dependence, and Persistence. The character dimensions include SelfDirectedness, Cooperativeness, and Self-Transcendence. While twin studies have supported the genetic contribution 
to temperament [10], character has also been reported to be heritable to some extent [11]. What remains to be further investigated are the psychosocial determinants of the temperament and character dimensions.

Among the many psychosocial correlates of temperament and character are perceived parenting styles in childhood. For example, Ruchkin, Eisemann et al. [8] used the EMBU (the Swedish acronym for Own Memories of Parental Rearing [12]) as a measure of the perceived rearing of male delinquent adolescents and normal controls and found that Novelty Seeking and Harm Avoidance were associated with lower parental warmth; Self-Directedness, Reward Dependence, and Persistence with parental warmth; and Cooperativeness with parental warmth and lower parental rejection. The PBI was used in three studies in this area. Reti, Samuels et al. [13] investigated a community resident population and found that Novelty Seeking was associated with parental Overprotection; Harm Avoidance with parental low Care and Overprotection (termed "affectionless control"); Reward Dependence with maternal care; Persistence with low maternal Overprotection; Self-Directedness with maternal Care and low parental Overprotection; and Cooperativeness and SelfTranscendence with maternal Overprotection. Kitamura, Tomoda et al. [14] studied a non-clinical population of young Japanese women and demonstrated that Self-Directedness and Cooperativeness were associated with parental Care. Kitamura and Kishida [15] studied 4000 university students in Japan, showing that among men, Reward Dependence was associated with parental Care, Self-Directedness with low paternal Care, and Self-Transcendence with maternal Care, whereas among women, Harm Avoidance was associated with parental Overprotection, Reward Dependence with parental Overprotection, and Self-Directedness with low parental Overprotection.

These studies, though suggesting a link between perceived rearing during childhood and temperament and character in adulthood, failed to take into consideration the association between Care and Overprotection between and within fathers and mothers as well as associations between different temperament and character dimensions and the prediction of character dimensions from temperament dimensions. It has been noted that parental Care and Overprotection are inversely correlated while paternal and maternal rearing styles are positively correlated [6]. Thus, it may be that paternal and maternal Care and Overprotection, though discrete to some extent, are composed of the single latent concept of rearing environment. According to Cloninger's theory, the development of character is based on temperamental profiles. In fact there are many studies suggesting the association between temperament and character dimensions (e.g., $[16,17])$. Hence, we hypothesize that perceived rearing during childhood can be viewed as a single construct, that perceived rearing will predict temperament and character dimensions, and that temperament dimensions will predict character dimensions, so that the effects of perceived rearing on character dimensions may be mediated via temperament dimensions.

\section{METHODS}

\section{Participants}

One thousand and ninety-eight college students from three universities and one college in the Tokyo area particip- ated in this study. Because 109 students did not complete the questionnaire and we were interested in adolescents and young adults between the ages of 18 and 25, data from 836 students $($ men $=113$, women $=787)$ who were under 26 years old and who completed the questionnaire were included in the subsequent analyses. Their mean (SD) age was $18.9(0.9)$ years old.

\section{Procedure}

Students completed the questionnaire anonymously during one class period. The study was approved by the Ethical Committee of the National Institute of Mental Health, Kohnodai Campus, Japan.

\section{Measures}

Temperament and Character. The Temperament and Character Inventory (TCI) assesses personality by measuring four temperament dimensions (Novelty Seeking, Harm Avoidance, Reward Dependence, and Persistence) and three character dimensions (Self-Directedness, Cooperativeness, and Self-Transcendence).The original TCI was a true-false questionnaire consisting of 240 items but Kijima et al. [17] reported better internal consistency with a 4-point scale rather than a dichotomous scale. We used the 4-point scale in the present study. We used 125 items, with responses to each item ranging between 1 (strongly disagree) and 4 (strongly agree).

Perceived parenting in childhood. The PBI is a selfreport instrument measuring the perception of being parented up to the age of 16 . It contains 12 Care and 13 Overprotection items rated on a 4-point scale (0 to 3 ), each of which describes a specific parental attitude toward the subject. Higher scores indicate higher Care or higher Protection experiences. The Japanese version of the PBI was retranslated back into English to ensure that the translation corresponded with the meaning of the original instrument [18].

\section{Statistical Analysis}

First, we correlated all the variables used in this study. Then we tested our hypothesis using structural equation modelling (SEM). We used confirmatory factor analysis (CFA) to determine whether all four PBI subscales fell under the rubric of the latent construct, "perceived parenting" (Fig. 1). After confirming the single factor structure of the PBI, we created a structural regression model (Fig. 2). We posited that perceived parenting would be associated with temperament, and that temperament dimensions would in turn be associated with character dimensions. Perceived parenting would also be directly associated with character dimensions.

$\mathrm{X}^{2} / \mathrm{df}$, comparative fit index (CFI), and root mean square error of approximation (RMSEA) with a $90 \%$ confidence interval (CI) were used as goodness-of-fit indices. According to conventional criteria, $\mathrm{X}^{2} / \mathrm{df}<3, \mathrm{CFI}>.95$, and $\mathrm{RMSEA}<$ 0.08 indicate an acceptable fit and $\mathrm{X}^{2} / \mathrm{df}<2$, CFI $>.97$, and RMSEA $<0.05$ indicate a good fit $[19,20]$. In order to improve the model's fit with the data, modification indices were used and new covariance estimates were consecutively added. We paid the most attention to ensuring that respecifications suggested by modification indices made 
theoretical or common sense [21]. Although ideally covariances would be set between observed variables, this approach is not permitted in AMOS. Therefore, we set a covariance between the error variables of two observed variables. This means that we posited covariation between two variables that could be explained by the latent variable by which the two are predicted.

SPSS-18 and AMOS-18 were used for statistical analysis.

\section{RESULTS}

In a correlation coefficient matrix we observed that parental low Care and Overprotection (affectionless control) were correlated with low Self-Directedness, while paternal affectionless control and maternal Overprotection were correlated with low Cooperativeness. Parental low Care was correlated with Novelty Seeking whereas parental Overprotection was correlated with Harm Avoidance and low Persistence. We also observed correlations within and between some temperament and character dimensions. Thus, among temperament dimensions, Novelty Seeking was correlated with Reward Dependence and inversely correlated with Harm Avoidance and P. Harm Avoidance was correlated with Reward Dependence and inversely correlated with Persistence. Among character dimensions, Cooperativeness was correlated with Self-Directedness and Self-Transcendence. Between temperament and character dimensions, Novelty Seeking was correlated with Selftranscendence; Harm Avoidance was inversely correlated with Self-Directedness, Cooperativeness, and Self-Transcendence; Reward Dependence was correlated with Cooperativeness and Self-Transcendence but inversely with Self-Directedness; and
Persistence was correlated with Self-Directedness, Cooperativeness, and Self-Transcendence (Table 1).

A CFA of the four PBI subscales (paternal and maternal Care and Overprotection) showed good fit with the data (Fig. 1). A "perceived parenting" construct had significant positive paths towards paternal and maternal Care and significantly negative paths towards paternal and maternal Overprotection. Therefore, this latent construct reflects an optimal rearing environment that is characterised by high care and respect for autonomy.

The structural regression model showed that Novelty Seeking and Harm Avoidance were associated with low SelfDirectedness and low Cooperativeness; Novelty Seeking, Reward Dependence, and Persistence were associated with Self-Transcendence; and Reward Dependence was associated with Cooperativeness. It also showed that Perceived Parenting was associated with low Harm Avoidance and high Persistence. Perceived Parenting was also directly associated directly with Self-Directedness, Cooperativeness, and low Self-Transcendence (Fig. 2). This model met the criteria of acceptable fit.

Because the majority of the present participants were women, we reanalysed the data in the same manner but only among female students. This resulted in virtually the same results (Figure not shown).

\section{DISCUSSION}

In summary, the present results partly support our hypothesis. Perceived parenting can be viewed as a single latent variable; Self-Directedness and Cooperativeness are

Table 1. Correlations, Means, SDs, and Internal Consistency of the TCI and PBI Scores

\begin{tabular}{|c|c|c|c|c|c|c|c|c|c|c|c|c|c|}
\hline & 1 & 2 & 3 & 4 & 5 & 6 & 7 & 8 & 9 & 10 & 11 & 12 & 13 \\
\hline 1 Novelty Seeking & --- & & & & & & & & & & & & \\
\hline 2 Harm avoidance & $-.30 * * *$ & --- & & & & & & & & & & & \\
\hline 3 Reward Dependence & $.18 * * *$ & $.08 *$ & --- & & & & & & & & & & \\
\hline 4 Persistence & $-.18 * * *$ & $-.15 * * *$ & .07 & --- & & & & & & & & & \\
\hline 5 Self Directedness & -.06 & $-.48 * * *$ & $-.08 *$ & $.20 * * *$ & --- & & & & & & & & \\
\hline 6 Cooperativeness & .02 & $-.14 * * *$ & $.42 * * *$ & $.18 * * *$ & $.23 * * *$ & --- & & & & & & & \\
\hline 7 Self-Transcendence & $.20 * * *$ & $-.14 * * *$ & $.15 * * *$ & $.26 * * *$ & .01 & $.12 * *$ & --- & & & & & & \\
\hline 8 Fathers' Care & $-.12 * *$ & -.05 & .05 & .01 & $.10 * *$ & $.09 *$ & .02 & --- & & & & & \\
\hline 9 Fathers' Over Protection & .06 & $.10 * *$ & -.04 & $-.11 * *$ & $-.21 * * *$ & $-.14 * * *$ & .04 & $-.36 * * *$ & --- & & & & \\
\hline 10 Mothers' Care & $-.09 * *$ & -.01 & .04 & .04 & $.09 * *$ & .06 & -.00 & $.53 * * *$ & $-.53 * * *$ & --- & & & \\
\hline 11 Mothers' Over Protection & .06 & $.13 * * *$ & -.03 & $-.10 * *$ & $-.22 * * *$ & $-.14 * * *$ & .05 & $-.33 * * *$ & $.74 * * *$ & $-.56 * * *$ & --- & & \\
\hline 12 Age & -.04 & $-.12 * * *$ & $-.15 * * *$ & $.12 * *$ & $.15 * * *$ & $-.08 *$ & .05 & $.07 *$ & $-.17 * * *$ & $.14 * * *$ & $-.12^{* *}$ & --- & \\
\hline 13 Gender (1 - man; 2 -woman $)$ & -.04 & $-.13 * * *$ & $-.24 * * *$ & $.09 * *$ & $.14 * * *$ & $-.16 * * *$ & .02 & .00 & $-.15 * * *$ & $.10 * *$ & $-.09 *$ & $.43 * * *$ & --- \\
\hline Number of items & 19 & 20 & 16 & 5 & 25 & 25 & 15 & 12 & 13 & 12 & 13 & 1 & 1 \\
\hline Range & $7-53$ & $3-57$ & $3-47$ & $0-15$ & $11-72$ & $9-66$ & $1-40$ & $0-28$ & $0-31$ & $0-27$ & $0-29$ & $18-25$ & $1-2$ \\
\hline$M$ & 28.5 & 36.2 & 31.4 & 8.26 & 35.0 & 45.9 & 16.2 & 16.8 & 13.4 & 18.8 & 13.5 & 18.9 & 1.13 \\
\hline$S D$ & 7.2 & 7.8 & 6.1 & 2.71 & 8.3 & 7.4 & 6.3 & 5.9 & 6.9 & 6.7 & 6.9 & 0.9 & \\
\hline Cronbach's Alpha & .768 & .829 & .745 & .693 & .795 & .779 & .806 & .397 & .573 & .271 & .506 & NA & NA \\
\hline
\end{tabular}


predicted by both low Novelty Seeking and Harm Avoidance as well as high Reward Dependence and Persistence; and Self-Directedness and Cooperativeness are also predicted by optimal perceived parenting directly and indirectly through the effect of perceived parenting on Harm Avoidance and Persistence.

All three character dimensions were associated with perceived parenting during childhood whereas this was the case for only two of the four temperament dimensions. Many previous studies have regarded Care and low Overprotection (respecting children's autonomy) as an optimal rearing style. This style was associated with high Self-Directedness, high Cooperativeness and low Self-transcendence. People with high Self-Directedness and Cooperativeness are described as organized or creative [9] (p. 46). These character dimensions mature with age while Self-transcendence decreases with age [16] (p. 87)). The link between affectionless control and low Self-Directedness and Cooperativeness found in this study is in line with past reports (e.g., $[14,22])$. In addition, this study was unique in demonstrating that this link was both direct and indirect via temperament dimensions such as low Harm Avoidance and high Persistence. Almost all past studies treated temperament and character dimensions as being on the same order in terms of their association with perceived parenting styles. Furthermore, our study used an SEM, which allowed us to take into consideration the

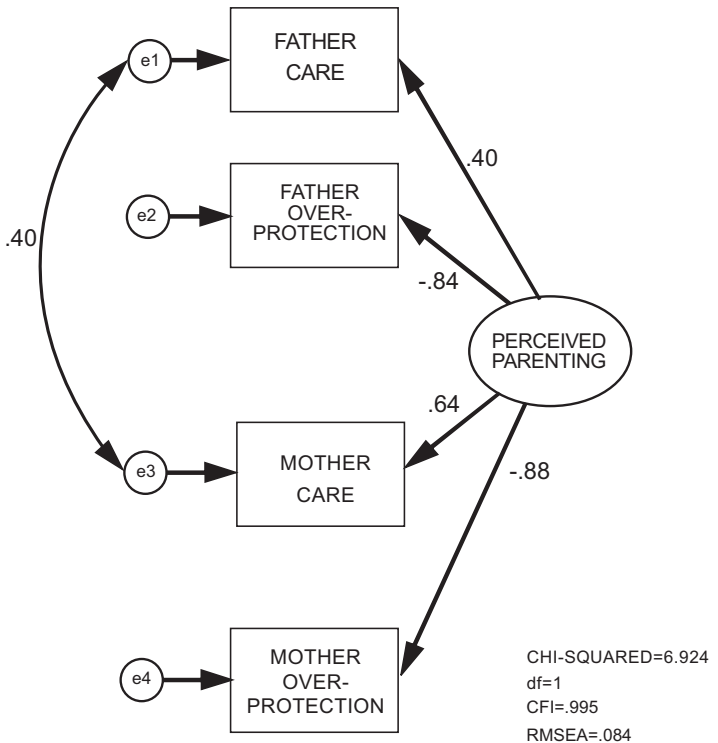

RMSEA $=.084$

$90 \% \mathrm{Cl}$ OF RMSEA LOWEST $=.034$ $90 \% \mathrm{Cl}$ OF RMSEA HIGHEST $=.148$ $\mathrm{AIC}=24.924$

Fig. (1). Confirmatory factor analysis of the PBI subscales.

correlation between character dimension error terms. Hence, we avoided possible confounding in the link between

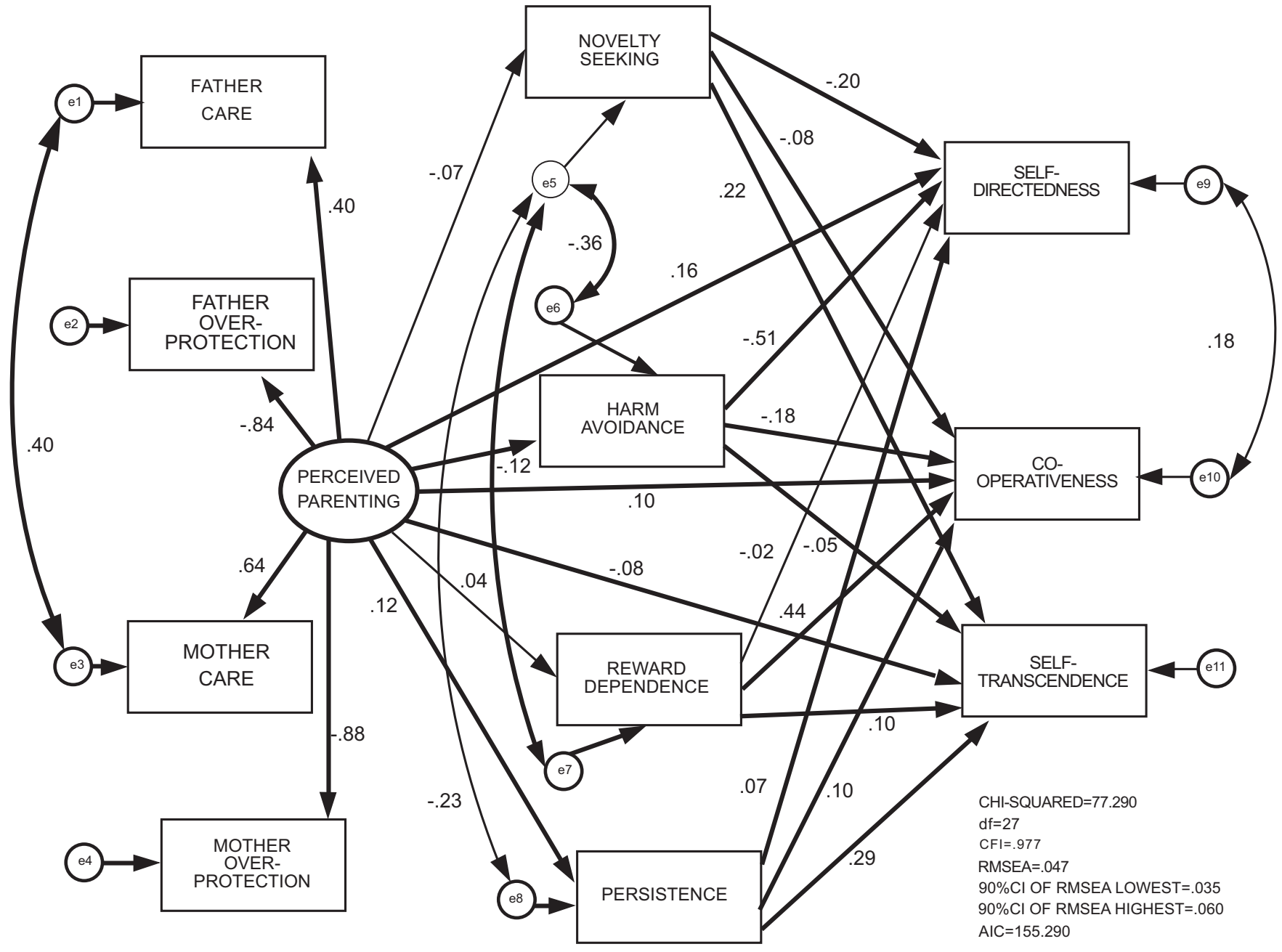

Fig. (2). Structural regression model. 
optimal parenting styles and Self-Directedness and Cooperativeness.

Contrary to previous reports, this study showed that Harm Avoidance and Persistence, both temperament dimensions, were associated with optimal parenting styles. This discovery may have resulted from creating a perceived parenting construct rather than treating each subscale of the fathers' and mothers' PBI separately and because associations between the temperament and character dimensions were statistically removed. Our findings suggest that the temperament dimensions, though heritable to some extent, are partly determined by how people were raised during the early years of life.

The limitations of this study should be considered. Firstly, all information was obtained directly from the participants; hence self-reports are subject to bias. However, peer assessment of temperament and character in adults is not feasible. It is also difficult for individuals to measure perceived parenting in others unless they are questioning a twin or sibling with whom they lived together as children or adolescents. A time-consuming longitudinal study may shed more light on this issue.

Secondly, we examined college students who fell within a rather narrow age range. The gender ratio in this study was heavily skewed towards women. This is because we recruited participants in a women's college as well as bothgender ones. An adult population with an equal gender balance could result in different findings. Our preliminary analysis demonstrated that the results would not change substantially if the population was restricted to women. Further studies are needed to clarify whether men would show different patterns of the relationships between the perceived parenting and personality. It may also be that older individuals' personalities are less influenced by perceived parenting during the early years of life.

Thirdly, people's retrospective memories of how they were raised may be influenced by their mood states. We cannot address this issue because we did not assess participants' moods, for instance, depression and anxiety. However, we do not think this is a great drawback because there have been ample investigations showing minimal influence of respondents' mood on their parenting memories [23-27].

Another fourth limitation of this study is the conceptualization of the personality model. Following Cloninger's theory, we posited that character dimensions develop on the basis of temperament dimensions. This is, however, an issue to be investigated further. Character dimensions may precede temperament dimensions. Alternatively, the two may influence each other.

Taking these limitations into consideration, the present study suggests that adolescents' and young adults' personality and character dimensions in particular are associated with perceived optimal parenting characterised by high care and respect for children's autonomy.

\section{REFERENCES}

[1] Baumrind D. Patterns of parental authority and adolescent autonomy. New Dir Child Adoles Dev 2005; 108: 61-9.
[2] Rohner RP, Pettengill SM. Perceived parental acceptance-rejection and parental control among Korean adolescents. Child Dev 1985; 56: 524-8.

[3] Parker GB. Parental Overprotection: A risk factor in psychosocial development. New York: Grune and Stratton 1983.

[4] Parker G, Tupling H, Brown LB. A parental bonding instrument. Br J Med Psychol 1979; 52: 1-10.

[5] Kitamura T, Sugawara M, Sugawara K, Toda MA, Shima S. Psychosocial study of depression in early pregnancy. $\mathrm{Br} \mathrm{J}$ Psychiatry 1996; 168: 732-8.

[6] Uji M, Tanaka N, Shono M, Kitamura T. Factorial structure of the Parental Bonding Instrument (PBI) in Japan: A study of cultural, developmental, generational, and sexual influences. Child Psychiatry Hum Dev 2006; 37: 115-32.

[7] Loranger AW, Oldham JM, Tulis EH. Familial transmission of DSM-III Borderline personality disorder. Arch Gen Psychiatry 1982; 39: 795-9.

[8] Ruchkin VV, Eisemann M, Hägglöf $B$, Cloninger CR. Interrelations between temperament, character, and parental rearing in male delinquent adolescents in Northern Russia. Compr Psychiatry 1998; 39: 225-30.

[9] Cloninger CR. Feeling good: the science of well-being. New York: Oxford University Press 2004.

[10] Heath AC, Cloninger CR, Martin NG. Testing a model for the genetic structure of personality: A comparison of the personality system of Cloninger and Eysenck. J Pers Soc Psychol 1994; 66: $762-75$.

[11] Gillespie NA, Cloninger CR, Health AC, Martin NG. The genetic and environmental relationship between Cloninger's dimensions of temperament and character. Pers Individ Dif 2003; 35: 1931-46.

[12] Perris C, Jacobsson L, Lindström H, von Knorring L, Perris H. Development of a new inventory assessing memories of parental rearing behaviour. Acta Psychiatr Scand 1980; 61(4): 265-74.

[13] Reti IM, Samuels JF, Eaton WW, Bienvenu OJ, Costa PT Jr, Nestadt G. Influence of parenting on normal personality traits. Psychiatry Res 2002; 111: 55-64.

[14] Kitamura T, Tomoda A, Kijima N, Sakamoto S, Tanaka E, Iwata N. Correlates of retrospective early life experience with personality in young Japanese women. Psychol Rep 2002; 91: 263-74.

[15] Kitamura T, Kishida Y. Early Experiences and development of personality: a study of the temperament and character inventory in 4000 university students in Japan. In: Columbus F, Ed. Focus on lifestyle and health research Hauppauge: Nova Science Publishers 2005.

[16] Cloninger CR, Przybeck TR, Svrakic DM, Wetzel RD. The temperament and character inventory (TCI): A guide to its development and use. St. Louis: Center for Psychobiology of Personality Washington University 1994.

[17] Kijima N, Tanaka E, Suzuki N, Higuchi H, Kitamura T. Reliability and validity of the Japanese version of the temperament and character inventory. Psychol Rep 2000; 86: 1050-8.

[18] Kitamura T, Suzuki T. A validation study of parental bonding instrument in Japanese population. Jpn J Psychiatry Neurol 1993; 47: 29-36.

[19] Bentler PM. Comparative fit indexes in structural models. Psychol Bull 1990; 107: 238-46.

[20] Schermelleh-Engel1 K, Moosbrugger H, Müller H. Evaluating the fit of structural equation models: tests of significance and descriptive goodness-of-fit measures. Methd Psychol Res - Online 2003; 8: 23-74.

[21] Arbuckle JL, Wothke W. Amos 4.0 User's Guide. Chicago: SmallWaters; 1955-99.

[22] Kitamura T, Shikai N, Uji M, Hiramura H, Tanaka N, Shono S Intergenerational transmission of parenting style and personality: Direct influence or mediation? J Child Fam Stud 2009; 18: 541-56.

[23] Brewin CR, Andrews B, Gotlib IH. Psychopathology and early experience: A reappraisal of retrospective reports. Psychol Bull 1993; 113: 82-98.

[24] Gerlsma C, Arrindell WA, Emmerkamp PMG. Mood and memories of early parenting: Connotation of two parental rearing style questionnaires. Pers Individ Dif 1993; 12: 551-5.

[25] Gerlsma C, Das J, Emmerkamp PMG. Depressed patients' parental representations: Stability across changes in depressed mood and specificity across diagnoses. J Affect Disord 1993; 27: 173-81. 
[26] Gerlsma C, Kramer JJAM, Scholing A, Emmerkamp PMG. The influence of mood on memories of parental rearing practices. $\mathrm{Br} \mathrm{J}$ Clin Psychol 1994; 33: 159-72.
[27] Richter J, Eisemann M. Stability of memories of parental rearing among psychiatric inpatients. Clin Psychol Psychother 2000; 7: 256-61.

Received: November 4, 2010

(C) Takeuchi et al.; Licensee Bentham Open.

This is an open access article licensed under the terms of the Creative Commons Attribution Non-Commercial License (http://creativecommons.org/licenses/by$\mathrm{nc} / 3.0 /$ ) which permits unrestricted, non-commercial use, distribution and reproduction in any medium, provided the work is properly cited. 